\title{
Thermal bridge effect of vertical diagonal tie connectors in precast concrete sandwich panels: an experimental and computational study
}

\author{
Paul Klõšeiko, ${ }^{1,}$, Reimo Piir ${ }^{1}$, Marti Jeltsov², and Targo Kalamees ${ }^{3,1}$ \\ ${ }^{1}$ Tallinn University of Technology, Department of Civil Engineering and Architecture, 19086 Tallinn, Estonia \\ ${ }^{2}$ Estflow Consulting OÜ, Tartu, Estonia \\ ${ }^{3}$ Smart City Center of Excellence (Finest Twins), Tallinn University of Technology, Ehitajate tee 5, Tallinn, Estonia
}

\begin{abstract}
The purpose of this work was to quantify the thermal bridge effect of vertical diagonal tie connectors in precast concrete sandwich panels (PCSPs). Special interest was in cases where the use of rigid insulation (e.g. PIR) would leave air gaps between insulation boards and diagonal ties, thus intensifying the thermal bridge. A climate chamber experiment using 5 different joint types was performed to gather reference data for CFD model validation. In the experiment, natural convection was observed in joints where no additional insulation was used, i.e. in air cavities. Significantly larger heat fluxes were measured in these cavities compared to insulated joints. The thermal bridging effect was evaluated for a typical PCSP (thermal transmittance without thermal bridges $\mathrm{U}=0.11 \mathrm{~W} /\left(\mathrm{m}^{2} \cdot \mathrm{K}\right)$ ) using CFD software taking into account 3D heat conduction and convection. Simulation results indicate that diagonal ties without adjacent air cavities increased the average thermal transmittance (U-value) of the envelope by $8 \%$, diagonal ties with a $6 \mathrm{~mm}$ air cavity $-19 \ldots 33 \%$ and diagonal ties with a $10 \mathrm{~mm}$ air cavity $-45 \ldots 56 \%$. In conclusion, it was found that the joints in insulation caused by diagonal ties affect the overall thermal performance of the building envelope significantly when efforts are not made to fill the air cavities around the connectors.
\end{abstract}

\section{Introduction}

Global efforts towards improving the energy efficiency of buildings have led to an increasing motivation for using rigid thermal insulation materials in precast concrete sandwich panels (PCSPs). These materials often exhibit lower thermal conductivity compared to mineral wool, which has been the insulation material of choice for PCSP manufacturers and designers until recently.

The use of rigid insulation, however, introduces new problems in areas which could be considered thermally well-functioning when mineral wool insulation is used. One specific issue is the connection between the layers of concrete where stainless steel diagonal tie connectors are commonly used in Estonia. These are placed vertically between insulation boards typically at $0,6 \mathrm{~m}$ spacing as shown on Fig. 1.

As opposed to soft mineral wool, rigid insulation cannot be placed tightly around the diagonal ties and so a cavity is formed across the whole height and depth of the insulation layer. Insulation and diagonal tie manufacturers' technical manuals $[1,2]$ recommend filling this cavity with additional thermal insulation. This would avoid natural convection in the cavity, which in turn could increase the average thermal transmittance (Uvalue) of the building envelope significantly. However, there is evidence of Estonian PCSP manufacturers not adhering to these guidelines properly (see section 3.1 ).

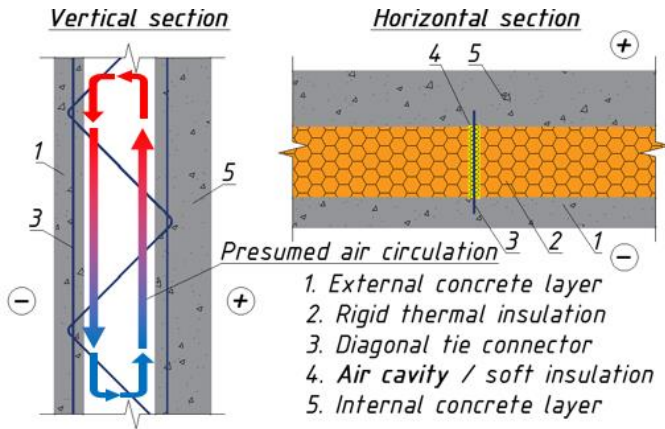

Fig. 1. Stainless steel diagonal tie connector and presumed natural convection between insulation boards (left), additional soft thermal insulation around diagonal tie (right)

Previous research in this field has mostly focussed on the effect of the steel connectors themselves without adjacent air cavities [3-7]. One prior computational analysis conducted by Klõšeiko [8] has considered the possibility of air cavities around the ties and their effect on the thermal performance of the building envelope.

In this work, the joint between 2 insulation boards caused by diagonal tie connectors was studied: - A climate chamber experiment was organised to measure the thermal performance of different joint types. - Models for calculating the thermal bridge effect were presented and were compared to measurements.

- The thermal bridge effect was estimated for typical PSCP structures.

\footnotetext{
* Corresponding author: paul.kloseiko@taltech.ee
} 


\section{Methods}

\subsection{Questionnaire and site observations}

A questionnaire was organised among Estonian PCSP manufacturers to gather input data for this work. Additionally, construction sites in Tallinn, Estonia were visited to examine PCSP insulation joints in reality.

Invitations to fill out the questionnaire were sent to all identified Estonian PCSP manufacturers, 12 in total. This included constituents of larger international corporations as well as smaller local manufacturers.

The construction sites visited relating to this work were chosen at the discretion of the authors and construction site management. 4 construction sites were visited, 2 of which displayed PCSPs with rigid insulation, mineral wool had been used for the other 2 .

\subsection{CFD modelling}

CFD software ANSYS® Fluent Academic Student 2019 R1 was used to estimate the thermal bridge effect of diagonal tie connectors in the climate chamber experiment and in typical PCSP structures, taking into account $3 \mathrm{D}$ heat and particle transfer. Input values for the simulations are given in Table 1.

Table 1. Input values for CFD simulations

\begin{tabular}{|c|c|c|}
\hline \multirow{2}{*}{ Variable } & \multicolumn{2}{|c|}{ Value } \\
\cline { 2 - 3 } & Test wall & $\begin{array}{c}\text { Typical } \\
\text { PCSP }\end{array}$ \\
\hline $\begin{array}{c}\text { PIR thermal } \\
\text { conductivity, } \mathrm{W} /(\mathrm{m} \cdot \mathrm{K})\end{array}$ & 0.019 & 0.023 \\
\hline $\begin{array}{c}\text { Thermal resistance of } \\
\text { interior surface, } \mathrm{m}^{2} \cdot \mathrm{K} / \mathrm{W}\end{array}$ & 0.08 & 0.125 \\
\hline $\begin{array}{c}\text { Thermal resistance of } \\
\text { exterior surface, } \mathrm{m}^{2} \cdot \mathrm{K} / \mathrm{W}\end{array}$ & 0.08 & 0.04 \\
\hline Interior temperature, ${ }^{\circ} \mathrm{C}$ & \multicolumn{2}{|c|}{+20} \\
\hline Exterior temperature, ${ }^{\circ} \mathrm{C}$ & \multicolumn{2}{|c|}{$0 ;-20$} \\
\hline Air flow models & Laminar; turbulent $(\mathrm{k}-\varepsilon)$ \\
\hline Gas type & Incompressible ideal gas \\
\hline
\end{tabular}

Fig. 2 shows the geometry and mesh density used for simulations of the typical PCSP structure, geometry of the test wall models corresponded to actual test wall dimensions (see section 2.4). Measured PIR thermal conductivity and surface thermal resistance values were used for test wall simulations, whereas the typical PCSP simulations were ran using the conductivity declared by the insulation manufacturer and surface resistances according to EN ISO 6946 [9]. A narrower model was used for typical PCSP simulations (corresponding to diagonal tie spacing of $450 \mathrm{~mm}$ ) to ensure adequate computational mesh density near the cavities as the number of finite elements was limited by the software. Computational mesh density was also varied in simulations for test wall with diagonal tie (Fig. 3)

For validation of the CFD simulations, the EN ISO 10211 criterion was used, i.e. the sum of all heat flows entering the object, divided by half the sum of the absolute values of all heat flows, shall be less than 0.0001 . Continuity, velocity and energy absolute residual criteria were set to $\leq 10 \mathrm{E}-6$.
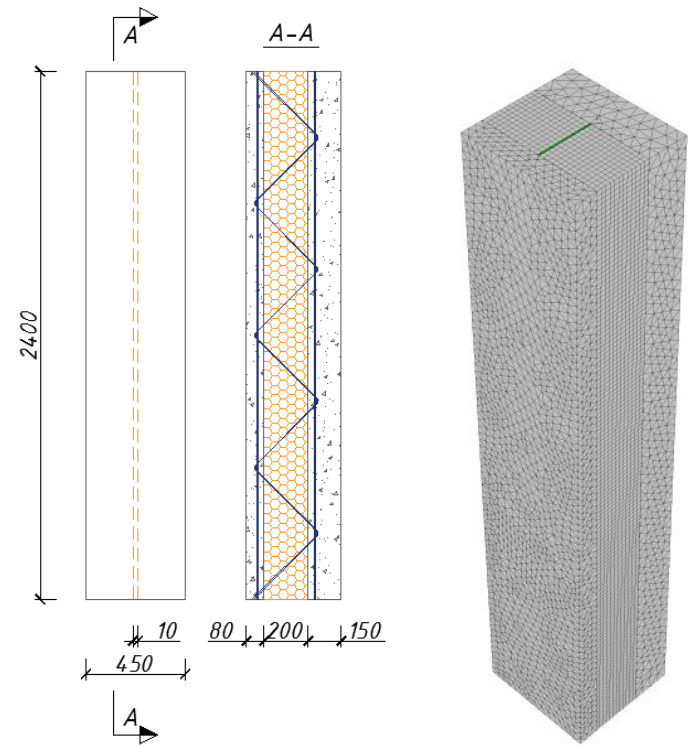

Fig. 2. Geometry used for CFD modelling of typical PCSP structure (left); computational mesh density in 3D (right). Screenshot courtesy of ANSYS, Inc.

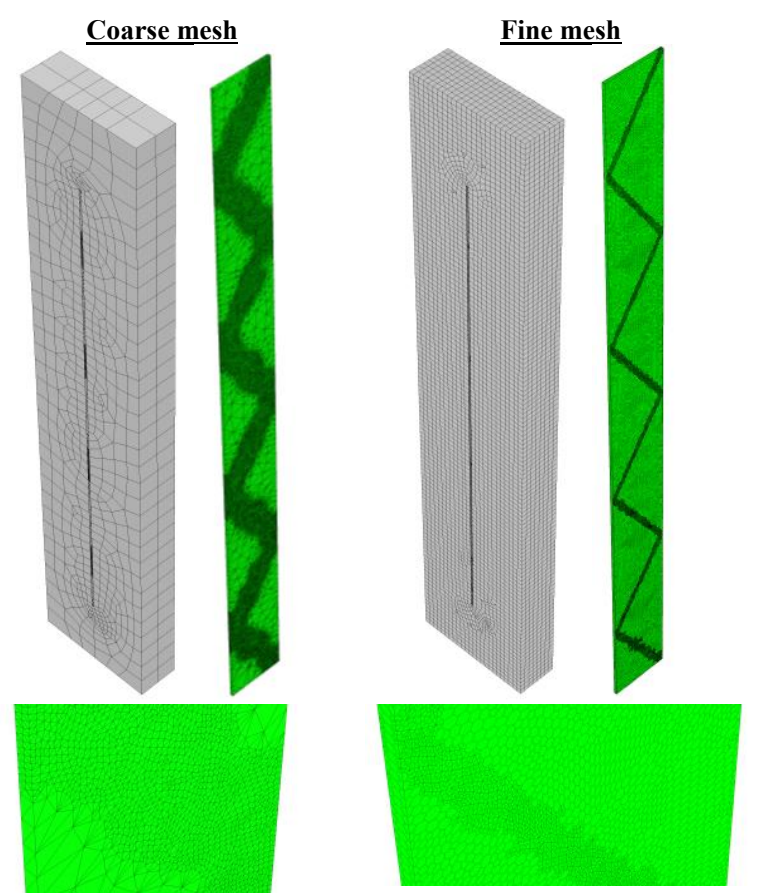

Fig. 3. Two different computational mesh densities for test walls with diagonal tie: coarse (left) and fine (right). Whole structure (top grey), air cavity (top green) and air cavity at diagonal tie (bottom). Screenshots courtesy of ANSYS, Inc.

\subsection{EN ISO 6946 method}

The thermal bridge effect of diagonal ties for typical PCSPs was also estimated using the simplified method provided by EN ISO 6946, annex F. According to this standard, corrections are applied to the thermal transmittance of the structure to account for air cavities and mechanical fasteners. 


\subsection{Climate chamber experiment}

A climate chamber experiment was organised to measure the thermal performance of different joint types and to gather reference temperature, heat flux and air velocity data for validation of calculation models. The test structure consisted of $200 \mathrm{~mm}$ thick PIR boards with the following $10 \mathrm{~mm}$ wide joints as shown on Fig. 4 :

- Air cavity without a diagonal tie

- Air cavity with a diagonal tie

- Joint filled with a mineral wool strip (no diagonal tie)

- Joint filled with polyurethane foam (no diagonal tie)

- Joint filled with expanding foam tape (no diagonal tie)

Duct tape $(\mathrm{t}=0.3 \mathrm{~mm})$ was used to separate the gaps between insulation boards from the interior and exterior climate, forming the air cavities.

The test wall was monitored for interior and exterior surface temperatures and interior surface heat flux at the joint locations as well as at one reference point away from the joints. Exterior chamber temperatures ranged from +10 to $-30^{\circ} \mathrm{C}$ (with $10^{\circ} \mathrm{C}$ intervals), interior chamber temperature was set at $+20^{\circ} \mathrm{C}$. Air velocity was measured inside the cavities at $-20^{\circ} \mathrm{C}$ exterior chamber temperature.

The following sensors and loggers were used:

- Temperature sensor Onset Hobo TMC20-HD (accuracy $\pm 0.15^{\circ} \mathrm{C}$ ) fastened using tape and hot glue with logger UX120-006M

- Heat flux plate greenTEG gSKIN-XP (accuracy $\pm 3 \%$ ) fastened using thermal paste and tape with logger Grant Squirrel SQ2020 1F8

- Heat flux plate Hukseflux HFP03 (accuracy $\pm 6 \%$ ) fastened using thermal paste with logger Grant Squirrel SQ2020 1F8 for PIR 1D conductivity measurements

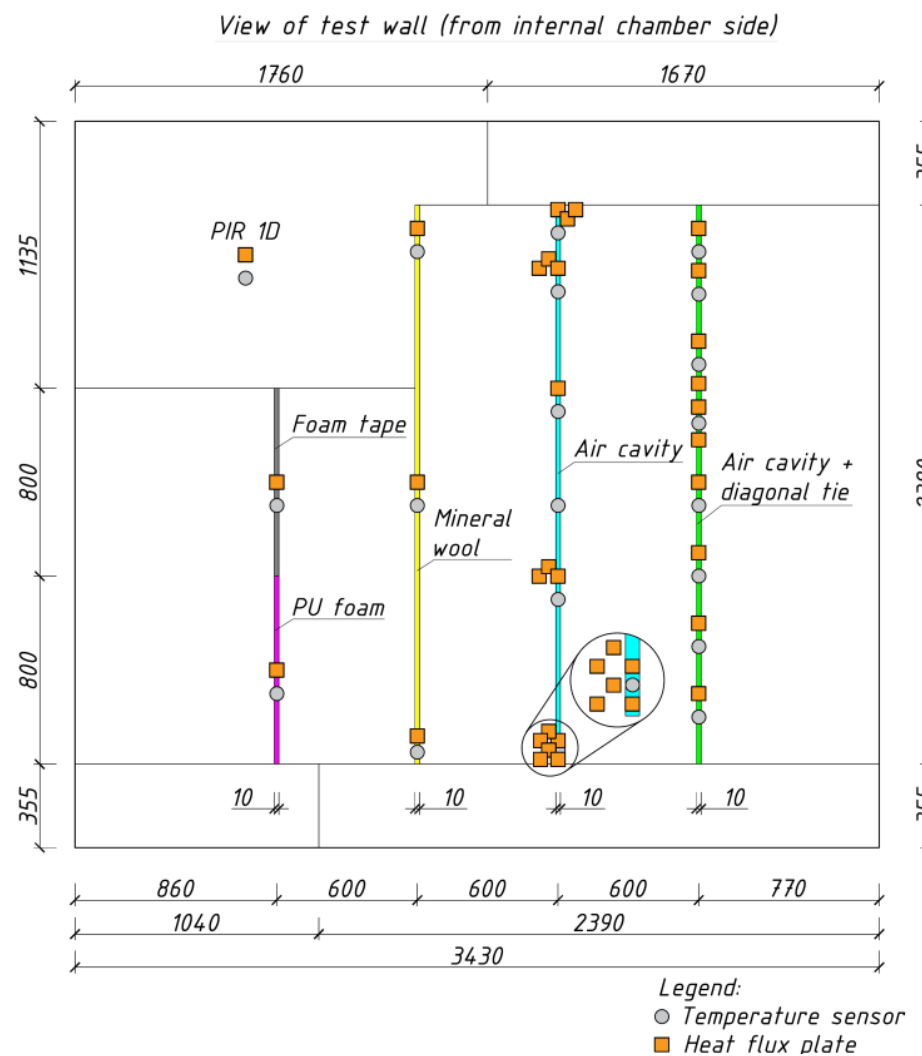

- Temperature sensor Pico PT100 1/10 DIN (accuracy $\pm 0.03^{\circ} \mathrm{C}$ ) with logger Pico PT-104 for calibration of the Onset temperature sensors

- Temperature sensor Siemens QFA3171 (accuracy $\pm 0.6^{\circ} \mathrm{C}$ ) built-in to the climate chamber for boundary condition measurements

- Thermal camera FLIR E95 with $42^{\circ}$ lens (accuracy $\pm 2^{\circ} \mathrm{C}$ ) for visual thermal imaging

- Anemometer Dantec 54T33 (accuracy $\pm 2 \%, \pm 0.02 \mathrm{~m} / \mathrm{s}$ )

Measurement results were averaged over periods of stable ambient temperatures for analysis.

\section{Results and discussion}

\subsection{Questionnaire and site observations}

Out of 12 PCSP manufacturers, 5 questionnaire answers were received. The following statements can be made based on the answers:

- Diagonal ties are the most commonly used PCSP connectors in Estonia

- The approach and techniques used in regard to providing additional insulation in diagonal tie joints varied widely

- Manufacturers' representatives were generally aware of the issue and deemed it worthy of further research

- The current state of PCSP manufacturing in Estonia concerning the issue at hand is satisfactory, although for most respondents there was room for improvement.

The following observations were made during visits to construction sites:

- The widths and filling of cavities varied considerably within each site and even within individual PCSPs

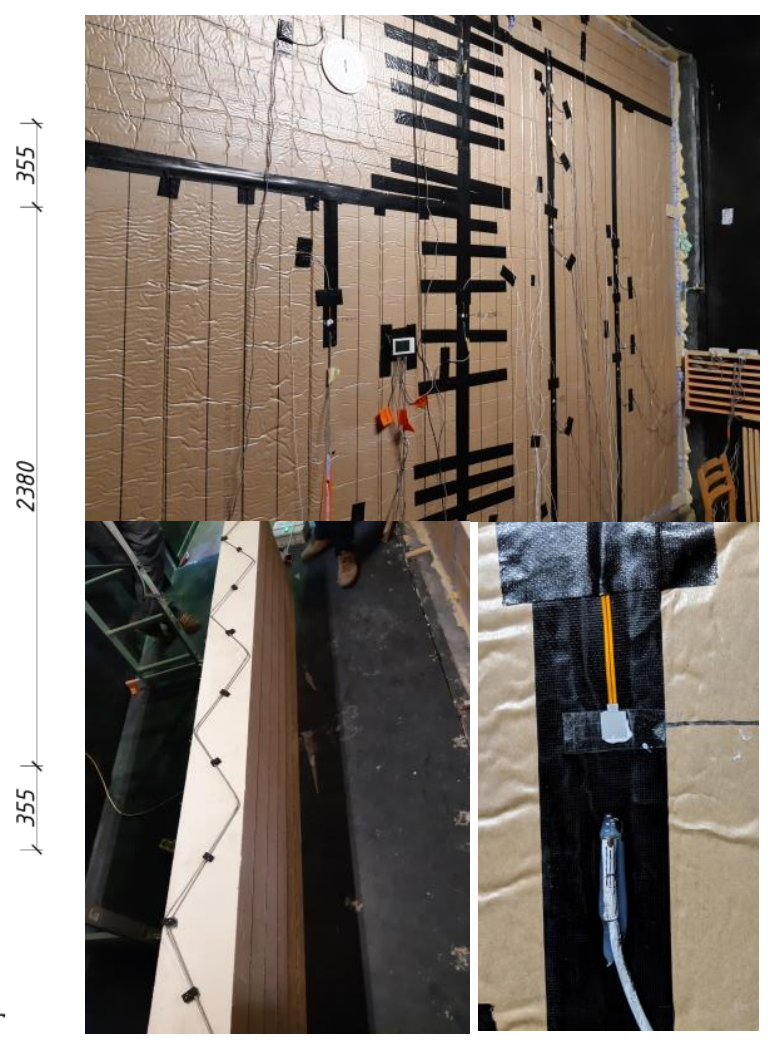

Fig. 4. View of test wall - sensor placement (left); photo of test wall (top right); placement of diagonal tie in cavity (middle bottom right); close-up photo of heat flux and temperature sensors at joint (far bottom right) 
- The vast majority of examined insulation joints measured less than $5 \mathrm{~mm}$ wide in case of mineral wool or were filled with PU foam for rigid insulation

- Air cavities between insulation boards were more common for rigid insulation, although issues were also determined for mineral wool joints

Fig. 5 illustrates some critical examined joints. It should be noted that mineral wool joints were also found to have gaps. Although the overall impression was positive, it might not have been indicative of the general situation due to the small numbers of sites visited and joints visible for inspection. A more accurate evaluation could have been attained through observation of the manufacturing process in PCSP factories.
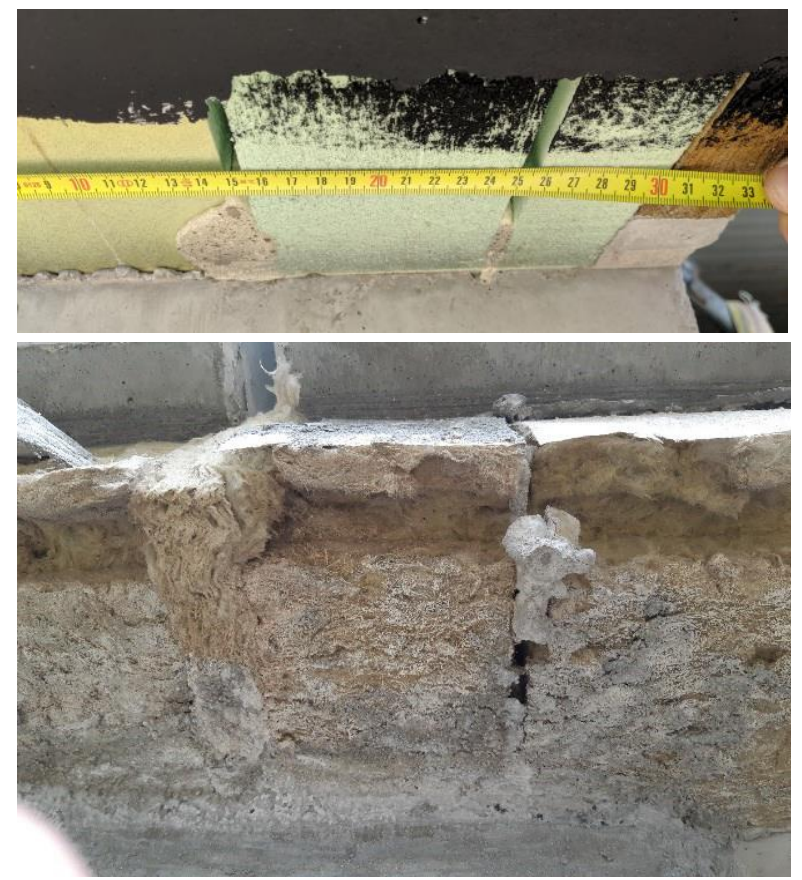

Fig. 5. Top: $\sim 10 \mathrm{~mm}$ wide air cavities between rigid insulation boards, not properly filled with foam. Bottom: cavity in mineral wool insulation. Concrete has flowed into the cavity during casting;

\subsection{CFD modelling of test wall}

Heat flux results from CFD modelling of the air cavities in the test wall are shown on Fig. 6. The simulated heat flux was nonconstant along the height of the cavities with the largest values at the bottom ends. In case of the cavity with a diagonal tie, local heat flux extremities were observed near the middle part of the cavity.

Computational mesh density and the ambient temperature difference were major factors for the simulation results, whereas the choice between laminar and turbulent air flow proved less significant. For some simulations (e.g. cavity with diagonal tie at $\Delta \mathrm{t}=40^{\circ} \mathrm{C}$ ), two separate sets of results were displayed due to the fineness of the mesh, i.e. several mesh nodes were generated on the same height in the cavity.

For the most part, diagonal ties were found to increase heat flux through the cavity. The effect of diagonal ties was more clearly defined in the upper half of the cavities, whereas in the bottom half the heat fluxes proved relatively similar.

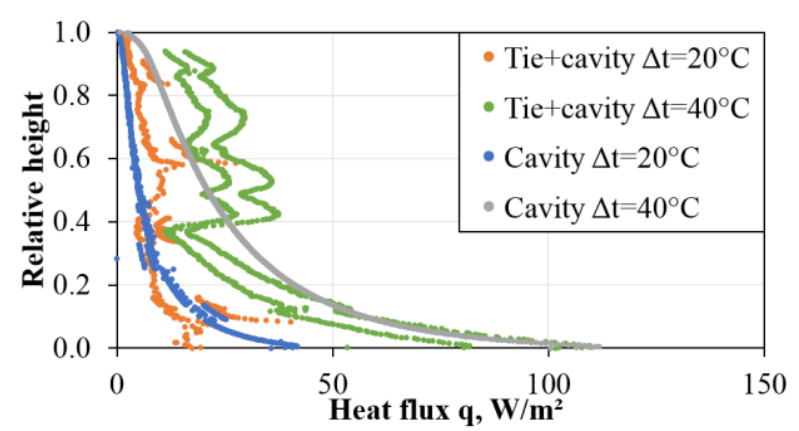

Fig. 6. Comparison of simulated interior surface heat fluxes on air cavities with and without diagonal tie (fine mesh, laminar air flow)

\subsection{Climate chamber experiment}

Heat flux measurement results from the air cavities are shown on Fig. 7 and Fig. 8. Heat fluxes were found to be nonconstant along the height of the joints, with the largest values measured at the bottom ends. The reason behind this was natural convection in the cavities. Air in the cavity would warm up along the interior surface of the joint, thus decreasing in density and moving upwards. Conversely, air would cool and move downwards along the exterior surface of the joint. At the bottom end of the joint, cold air would move back from the exterior to the interior side, creating a large temperature gradient and causing maximum heat flux.

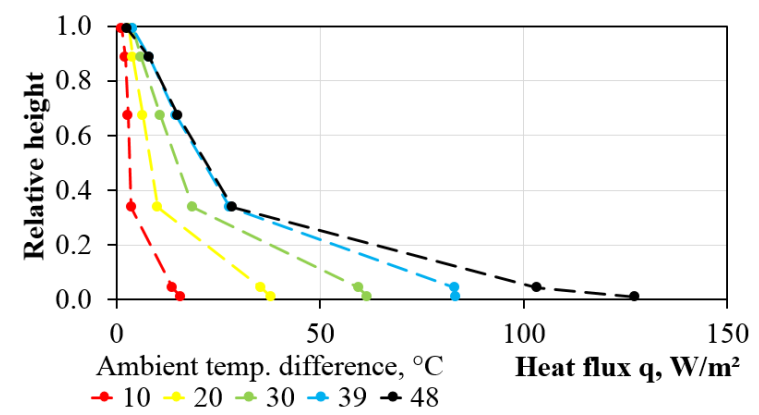

Fig. 7. Interior surface heat fluxes measured at different heights and ambient temperature differences on air cavity without a diagonal tie

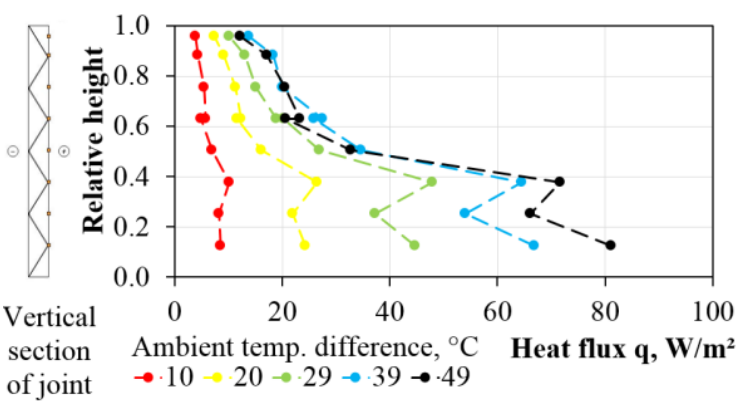

Fig. 8. Interior surface heat fluxes measured at different heights and ambient temperature differences on the air cavity with a diagonal tie

In the air cavity with a diagonal tie, local heat flux extremities were observed at the bends of the steel tie on the interior side, especially in the bottom half of the joint. This was because of the high thermal conductivity of stainless steel. In the top half of the joint with a diagonal 
tie, heat flux measurements produced results similar to those of the joint without a diagonal tie.

On the graphs, greater heat flux is shown in the cavity with no diagonal tie, because heat flux was measured closer to the bottom end in that cavity (20 and $100 \mathrm{~mm}$ from the bottom end vs. $300 \mathrm{~mm}$ in the tie cavity). On comparable measurement point heights, the heat flux through the tie joint exceeded that of the joint with no tie.

Among insulated joints (Fig. 9), the smallest heat flux was measured in the joint with a strip of mineral wool (MW). The heat fluxes measured through the other joints were only slightly greater and remained significantly lower than those of the air cavities.

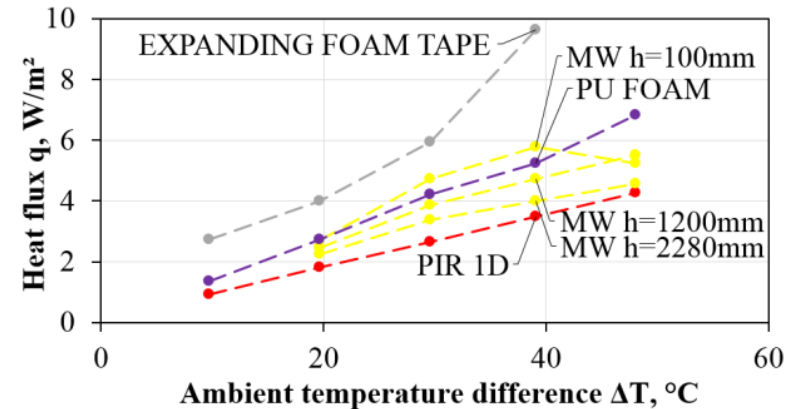

Fig. 9. Comparison of interior surface heat fluxes measured from joints with additional insulation and away from joints (PIR 1D)

These findings indicate that a diagonal tie increases the overall heat loss through the joint, although the effect of the tie itself is an order of magnitude smaller than the effect of natural convection in a non-insulated cavity.

Heat flux measurements in the joint with strip mineral wool produced similar results on different heights and the relationship between ambient temperature difference and heat flux was approximately linear. Therefore, it can be argued that no natural convection occurred in the joint.

The fastening of temperature sensors to the surface of the air cavities using tape and hot glue proved inadequate for the climate chamber experiment. The plastic-based glue acted as a significant insulator in front of the temperature sensors, where the overall thermal resistance was very small. For this reason, no temperature measurement results are shown in this work.

\subsection{Comparison of measurements to modelling}

The experimental and computational heat fluxes through the air cavities of the test wall were found to be in relatively good agreement as shown on Fig. 10. On the cavity without the diagonal tie, the calculated heat fluxes matched the experimental values within measurement accuracy for most of the height of the cavity. In the case with diagonal tie, the modelling also correlated to the measurements on the higher part of the wall. However, on the lower third, the measured heat fluxes were roughly $50 \%$ higher.

Comparing the cavities with and without a diagonal tie, the total measured and simulated heat flux was greater in the cavity with a diagonal tie, whereas the effect of thermal conduction through the steel tie itself was found to be secondary compared to the effect of the natural air convection in the cavity.

While total heat flows from the finely meshed models were about $10 \%$ higher than those of the coarse models, the difference between linear thermal transmittances calculated from them rose to $1 / 3$. Given the underestimation of heat fluxes in the lower part of the wall, the finer mesh should be preferred in order not to make an even worse non-conservative error.

Air velocity measurements achieved relatively good agreement with simulation results only in the cavity without a diagonal tie as shown on Fig. 11.

In the cavity with a diagonal tie, only locations of maximum velocities coincided between measurement and simulation results, whereas the measured velocities exceeded the simulated velocities significantly. These deviations could be caused by the shape and volume and exact position of the anemometers, which the CFD model does not account for. Also, in CFD models the diagonal tie was perfectly straight and a uniform gap of $0.5 \mathrm{~mm}$ was modelled between the tie and the sides of insulation boards. In reality the diagonal tie deformed slightly during construction of the test wall and larger gaps may have been left between the tie and the insulation boards.

For both cavities the measured air velocities were quite stable over time - the ratio between standard deviation and mean velocity was between $0.5 \ldots 3.5 \%$ (with the latter caused by measurement accuracy).
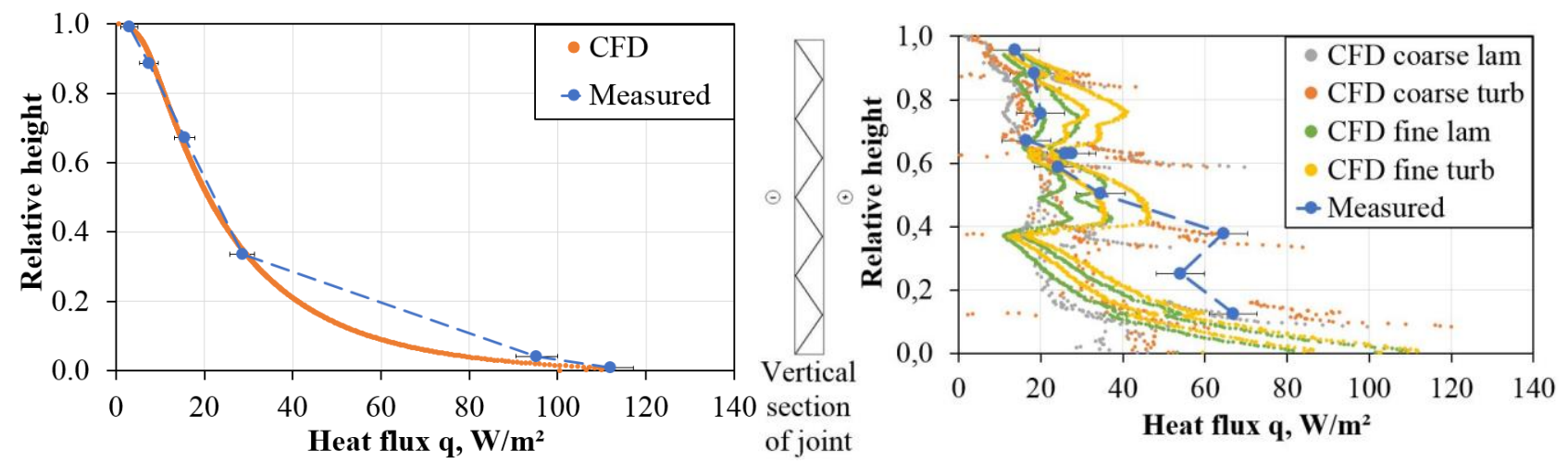

Fig. 10. Comparison of simulated and measured interior surface heat fluxes on the air cavity without a diagonal tie (left) and on the air cavity with a diagonal tie (right) at ambient temperature difference $\Delta \mathrm{t}=40^{\circ} \mathrm{C}$ 

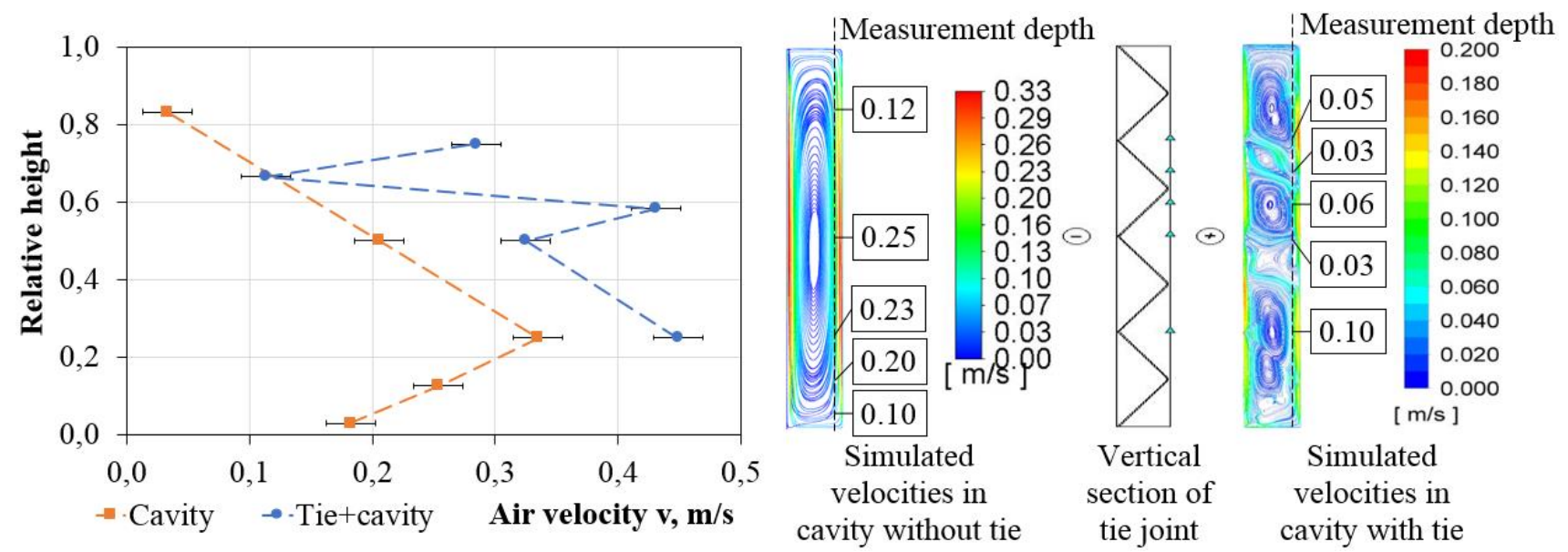

Fig. 11. Comparison of measured (left) and simulated air velocities and particle tracks in the air cavities at ambient temperature difference $\Delta \mathrm{t}=40^{\circ} \mathrm{C}$. Screenshots courtesy of ANSYS, Inc.

Both the experimental and computational results indicated that natural convection occurred in the air cavities. The heat fluxes were found to be nonconstant across the height of the joints, with the greatest values measured and simulated at the bottom ends. In these areas, air that had cooled along the exterior surface of the joint was moving back towards the interior surface of the joint, creating a large temperature gradient through the interior surface of the joint.

In simulations regarding the joint with a diagonal tie, three separate local circulations (see Fig. 11. (right)) were observed due to the direction of the tie. This explains the characteristic shape of the heat flux graph as the distribution of heat flux within each circulation was found to be similar to that of a whole cavity with no diagonal tie.

Overall, given that in real panels the geometry of the air cavity and the diagonal tie in it have a lot of randomness involved, the results of CFD modelling were considered to represent the measurements well enough.

\subsection{Thermal bridging in typical PCSP structures}

The thermal bridge effect was estimated for typical PCSP structures (diagonal tie spacing $450 \mathrm{~mm}$ ) using CFD simulations and the simplified method provided by EN ISO 6946. Simulation results are shown on Fig. 12.

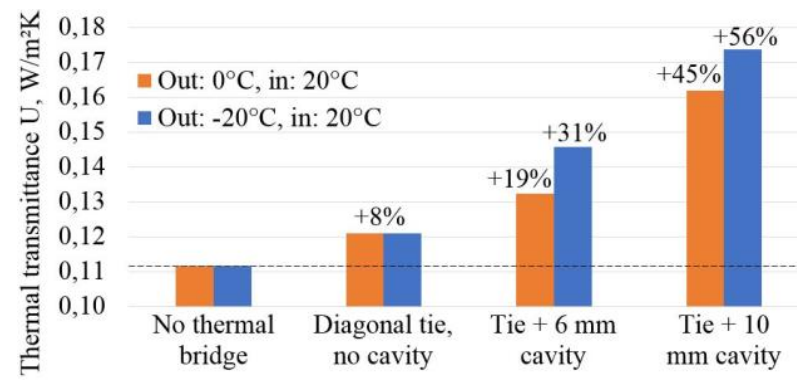

Fig. 12. Thermal bridge effect of diagonal ties in typical PCSP structures (CFD simulations, laminar air flow, diagonal tie spacing $450 \mathrm{~mm}$ )

CFD simulations indicated that a diagonal tie without an adjacent air cavity increased the thermal transmittance of the building envelope by $8 \%$, a diagonal tie with a 6 $\mathrm{mm}$ air cavity $-19 \ldots 31 \%$ and a diagonal tie with a $10 \mathrm{~mm}$ air cavity $-45 \ldots . .56 \%$.
The respective figures according to the EN ISO 6946 method were $4 \%, 13 \%$ and $39 \%$, whereas the primary consideration was the choice between coefficients describing the installation quality of insulation boards. Correction level 2, i.e. $\Delta U$ " $=0.04$ (or higher) should always be assumed when estimating the thermal bridge effect of diagonal ties with air cavities.

Even though the thermal bridging effect of diagonal ties with adjacent air cavities was proven to be significant, this is not a typical linear thermal bridge. In PCSP structures, the interior and exterior concrete layers act as buffers which distribute the thermal bridge effect over a wider surface area. In CFD simulations, the exterior surface temperature was only $\sim 0.5^{\circ} \mathrm{C}$ higher at the location of the insulation joint than elsewhere at an ambient temperature difference of $40^{\circ} \mathrm{C}$ (Fig. 13). This makes it very difficult to detect the thermal bridges after construction is finished.

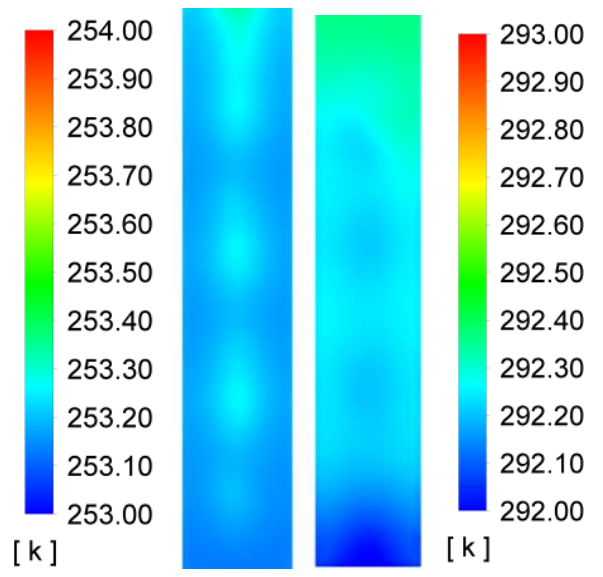

Fig. 13. Simulated temperatures on the exterior (left) and interior (right) surfaces of a typical PCSP structure at ambient temperature difference $\Delta \mathrm{T}=40^{\circ} \mathrm{C}$. Screenshots courtesy of ANSYS, Inc.

Ambient temperature difference also had a significant effect on the intensity of the thermal bridge, as determined by the experiment. Estimating the overall thermal bridge effect of diagonal ties in typical PCSP structures based on the average ambient temperature difference over an 8month heating period may prove to be inadequate. 


\section{Conclusion}

CFD simulations indicated that a diagonal tie without an adjacent air cavity increased the thermal transmittance of the building envelope by $8 \%$, a diagonal tie with a $6 \mathrm{~mm}$ air cavity $-19 \ldots 31 \%$ and a diagonal tie with a $10 \mathrm{~mm}$ air cavity $-45 \ldots 56 \%$.

To summarise, the following conclusions can be drawn from this work:

- Air cavities around diagonal ties significantly affect the overall thermal performance of PCSP structures

- Natural convection occurs in air cavities around diagonal ties if no additional insulation is provided in the joints

- Any kind of additional insulation around diagonal ties reduces the heat loss through the insulation joint by an order of magnitude compared to a non-insulated cavity.

- The most accurate estimate of the thermal bridge effect can be obtained using CFD simulations with a laminar flow model.

- EN ISO 6946 method underestimated the thermal bridge effect of PCSP connectors but proved adequate in terms of order of magnitude if air void correction level 2 is assumed.

- Neglecting or improperly filling the joints of rigid insulation around diagonal ties defeats the purpose of using the more efficient rigid insulation instead of mineral wool entirely.

This research was supported by the Estonian Centre of Excellence in Zero Energy and Resource Efficient Smart Buildings and Districts, ZEBE (grant No. 2014-2020.4.01.150016) funded by the European Regional Development Fund, by the Estonian Research Council (grant No. PRG483), Moisture safety of interior insulation, constructional moisture and thermally efficient building envelope, and by European Commission through the H2020 project Finest Twins (grant No. 856602). The authors would like to acknowledge S. Rannik, I. Sniker, M. S. Käärid, M. Kiil and K. V. Võsa for their contribution to this work.

\section{References}

1. Peikko Group, Ties and Connector Pins Technical Manual (2018)

2. Kingspan Group, Juhend nr 104 - Betoonelementide tootmine (2017)

3. J. Heikkinen, Betonielementtirakenteisen rakennuksen vaipan kylmäsiltatarkastelut (2011)

4. M. Salonvaara, J. Nieminen, Betonirakenteiden tuuletus ja lämmöneristävyys (2003)

5. O. Kinnane et al, 30th International PLEA Conference (2014)

6. Y. J. Kim and A. Allard, Energy Build. 80, 137-148 (2014).

7. F. Pozo-Lora and M. Maguire, Logan, Utah, (2019).

8. Klõšeiko, P. Raudbetoonpaneeli diagonaalsideme külmasilla hinnang. (2017)

9. EN ISO 6946:2017 Building components and building elements - Thermal resistance and thermal transmittance - Calculation methods (2017) 